\title{
Seroprevalence of Viral Hepatitis B or Hepatitis C Infection in HIV-infected Pregnant Women on Antiretroviral Therapy (ARV) in Abidjan (Côte d'Ivoire)
}

\author{
Leto Olivier Gogbe ${ }^{1,2}$, Thomas D'Aquin Toni ${ }^{1, ~ *, ~ J e a n-J a c q u e s ~ R e n a u d ~ D e c h i ~}{ }^{1,3}$, \\ Jean-Louis Philippe N'Din ${ }^{1,3}$, Emmanuel Brou ${ }^{1}$, Flore Fieni ${ }^{1}$, Roland Aby ${ }^{1}$, Kouadio Kouakou ${ }^{1}$, \\ Henri Chenal ${ }^{1}$, Jean David N'Guessan' \\ ${ }^{1}$ Abidjan Integrated Centre for Bioclinical Research, Abidjan, Côte d'Ivoire \\ ${ }^{2}$ UFR Biosciences, Felix Houphouët Boigny University, Abidjan, Côte d'Ivoire \\ ${ }^{3}$ UFR Medical Sciences, Felix Houphouët Boigny University, Abidjan, Côte d'Ivoire
}

Email address:

ta_toni@yahoo.com (T. D. Toni)

${ }^{*}$ Corresponding author

\section{To cite this article:}

Leto Olivier Gogbe, Thomas D'Aquin Toni, Jean-Jacques Renaud Dechi, Jean-Louis Philippe N'Din, Emmanuel Brou, Flore Fieni, Roland Aby, Kouadio Kouakou, Henri Chenal, Jean David N'Guessan. Seroprevalence of Viral Hepatitis B or Hepatitis C Infection in HIV-infected Pregnant Women on Antiretroviral Therapy (ARV) in Abidjan (Côte d'Ivoire). American Journal of BioScience.

Vol. 9, No. 4, 2021, pp. 141-146. doi: 10.11648/j.ajbio.20210904.15

Received: June 29, 2021; Accepted: July 15, 2021; Published: July 22, 2021

\begin{abstract}
Liver disease is a major cause of morbidity and mortality among people living with HIV (PLWH). Diagnosis of these co-infections should be a priority in HIV-infected pregnant women so that they can receive appropriate and effective treatment. However, the prevalence of these infections in this vulnerable population remains poorly documented in Côte d'Ivoire. The objective of this study is to assess the seroprevalence of hepatitis B virus (HBV) or hepatitis C virus (HCV) coinfections in HIV-infected pregnant women undergoing ARV treatment in Abidjan (Côte d'Ivoire). A cross-sectional study among HIV-infected pregnant women was conducted from September 2017 to May 2018 in Abidjan. HBV and HCV serological tests were performed with the electrochemiluminescence method "ECLIA" on Cobas E 411. A total of one hundred $(\mathrm{n}=100)$ HIV-infected pregnant women were included. The results showed that $6 \%(\mathrm{n}=6 / 100)$ of the HIV-infected pregnant women had positive HBV serology and no HIV-HCV co-infection was detected. Of the $100 \mathrm{HIV}$-infected pregnant women included in this study, $23 \%$ had undergone surgery. In this population, HBsAg was positive in $9 \%$ of patients and $\mathrm{HCV}$ antibodies were negative in all patients. The data from this study support the implementation of large-scale sentinel surveillance in Côte d'Ivoire in order to refine data on the prevalence and circulation of viral hepatitis B and C in high-risk populations such as pregnant women.
\end{abstract}

Keywords: HIV, HBV-HCV Coinfection, Prevalence, Pregnant Women

\section{Introduction}

Human immunodeficiency virus (HIV), viral hepatitis B virus $(\mathrm{HBV})$, and viral hepatitis $\mathrm{C}$ virus $(\mathrm{HCV})$ are the three most common chronic viral infections in the world $[1,2]$. According to the World Health Organization (WHO), of the 36.7 million people living with HIV (PLHIV) worldwide, 2.7

Million are also chronically infected with HBV and 2.3 million with $\mathrm{HCV}$ [3]. Because of the common mode of transmission of these three viruses (blood, sexual and mother-to-child routes, etc.), the number of HIV-HBV or HIV-HCV co-infected persons remains high [4]. According to the WHO, liver disease is a major cause of morbidity and mortality among PLHIV [3]. The therapeutic management of viral hepatitis $\mathrm{B}$ and $\mathrm{C}$ has evolved significantly over the last decade. For HBV, the use of nucleoside reverse transcriptase 
inhibitors (NRTIs) has effectively controlled viral replication [5]. As for $\mathrm{HCV}$, the development of direct-acting antivirals (DAAs) targeting the NS5A and NS5B gene proteins has enabled HCV eradication and the achievement of a "sustained virological response" (SVR) to treatment i.e., absence of replication twenty-four weeks after stopping treatment [6]. In Côte d'Ivoire, the National AIDS Control Program (NACP) recommends testing for hepatitis B surface antigen surface antigen (HBsAg) in the initial workup of PLHIV before initiation of first-line treatment [5]. However, this test is not routinely performed. In addition, testing for antibodies to $\mathrm{HCV}$ (Anti-HCV) is not included in the subsidized initial or follow-up work-up of PLWHA in Côte d'Ivoire [5]. Diagnosis of viral hepatitis B and C should be a priority in HIV-infected pregnant women in the context of prevention of mother-to-child transmission (PMTCT) so that they can receive appropriate and effective treatment such as tenofovir (TDF) and lamivudine (3TC) NRTI and DAAs. Indeed, children infected with $\mathrm{HBV}$ or $\mathrm{HCV}$, born to mothers co-infected with HIV and HBV or HCV are at higher risk of liver complications and death than children mono-infected with these viruses [6]. Although, the national technical advisory group for vaccination in Côte d'Ivoire (Ivory Coast) recommends hepatitis $B$ vaccine at birth [7]. It is in this context that this study was conducted to assess the seroprevalence of hepatitis $\mathrm{B}$ virus (HBV) and hepatitis $\mathrm{C}$ virus $(\mathrm{HCV})$ co-infections in $\mathrm{HIV}$-infected pregnant women undergoing ARV treatment in Abidjan (Côte d'Ivoire).

\section{Material and Methods}

This is a cross-sectional study conducted from September 2017 to May 2018 at the Abidjan Integrated Centre for Bioclinical Research (CIRBA). The study population consisted of HIV-infected pregnant women on ARVs. Informed consent was collected from patients to attest to their participation.

\subsection{Inclusion Criteria}

The patients selected were HIV-infected pregnant women on ARVs followed up in the context of HIV management or who came to CIRBA for biological monitoring of viral hepatitis $\mathrm{B}$ and $\mathrm{C}$.

\subsection{Non-inclusion Criteria}

Non-pregnant HIV-infected women were excluded. Similarly, pregnant HIV-infected women who expressed a refusal to participate in the study were not included.

\subsection{Biological Testing}

Venous blood samples were collected on EDTA tubes (BD Vacutainer ${ }^{\circledR}$ EDTA tubes). The plasma was obtained after centrifugation of the tubes at $3500 \mathrm{rpm}$ for 5 minutes. The first serological test was performed with the DetermineTM HIV-1/2 rapid diagnostic test (TROD) (Inverness Medical, USA) to confirm the presence of HIV antibodies in the included patients. Plasma was tested by electrochemiluminescence "ECLIA" on Cobas E 411 (Roche Diagnostics GmBH, Mannheim, Germany) for research antiHBs antibodies (Ac anti HBs) with the HBsAg II kit (Roche Diagnostics GmBH, Mannheim, Germany) and for research anti-HCV antibodies with the Anti-HCV II kit (Roche Diagnostics GmBH, Mannheim, Germany). Then, the quantification of plasma HIV-1 RNA was performed with the Cobas AmpliPrep/Cobas TaqMan HIV-Test, v2.0 kit with a threshold of 20 copies $/ \mathrm{mL}$. Transaminases (ALAT) were determined and quantified with the Cobas Integra/Cobas $\mathrm{c}$ system Alanine Amino Transferase (ALAT) cassettes on the Cobas C 311 Analyzer (Roche Diagnostics GmbH Germany) the analyses were performed according to the manufacturer's recommendations.

\subsection{Data Analysis}

SPSS Statistics 17.0.1 software was used for statistical analyses of prevalence and socio-demographic data.

\section{Results}

\subsection{Social and Biological Characteristics of the Included Patients}

A total of $100 \mathrm{HIV-infected} \mathrm{pregnant} \mathrm{women} \mathrm{who} \mathrm{were}$ followed or came to CIRBA for biological monitoring of hepatitis $\mathrm{B}$ and $\mathrm{C}$ were included in this study. The median age of the patients was 33 years (20-44 years). The median HIV-1 RNA level was 31850 copies/mL (range 20-63700 copies $/ \mathrm{mL}$ ). The median ALAT transaminase level was 44 $\mathrm{IU} / \mathrm{mL}$ (range 6-82 IU/mL). All pregnant women included were on ARV therapy (Table 1).

Table 1 shows that $70 \%$ of the included women had HIV-1 RNA levels below the threshold of detectability (HIV-1 RNA $<20$ copies $/ \mathrm{mL}$ ). On the other hand, $3 \%$ of the women included had an RNA-HIV-1 level higher than 1000 copies/mL (RNA-HIV-1 $>1000$ copies $/ \mathrm{mL}$ ) and $27 \%$ of the women had an intermediate viral load $(20<$ RNA-HIV-1 < 1000 copies $/ \mathrm{mL}$ ).

In terms of quantitative ALAT assays, $92 \%$ of the patients included had ALAT levels below or equal to normal $(\mathrm{N}=40$ $\mathrm{IU} / \mathrm{mL}$ ). However, $8 \%$ of the patients had an ALAT level above normal. The patients included were all on antiretroviral therapy (ART) for at least one year.

Table 1. Social and biological characteristics of HIV-infected pregnant women included in the study.

\begin{tabular}{ll}
\hline Characteristics & Values \\
\hline Numbers $(\mathrm{N})$ & 100 \\
Median age (year; range) & $33(20-44)$ \\
Median HIV-1 RNA (copies/mL) & 31850 \\
HIV-1 RNA $\leq 20$ copies/mL $(\%)$ & 70 \\
HIV-1 RNA $>1000$ copies/mL $(\%)$ & 3 \\
$20<$ HIV-1 RNA $<1000$ copies/ mL (\%) & 27 \\
Median ALAT $(\mathrm{IU} / \mathrm{mL})$ & 44 \\
ALAT $\leq 40$ IU/mL $(\%)$ & 92 \\
ALAT $>40$ IU/mL $(\%)$ & 8 \\
\hline
\end{tabular}




\subsection{Treatment Regimen for HIV-infected Pregnant Women}

HIV-infected pregnant women were on first-line or second-line treatment. The treatment regimen for patients on first-line treatment, 94\%, consisted of 2 NRTIs and 1 NNRTI $(\mathrm{TDF}+3 \mathrm{TC}+\mathrm{EFV})$. The treatment regimen of patients in second line treatment was composed of 2 NRTIs +1 PI: $\mathrm{ABC}+3 \mathrm{TC}+\mathrm{LPV} / \mathrm{r}, \quad$ in $1 \% \quad(\mathrm{n}=1 / 100)$ of patients; $\mathrm{TDF}+3 \mathrm{TC}+\mathrm{LPV} / \mathrm{r}$ in $2 \% \quad(\mathrm{n}=2 / 100)$ of patients or $\mathrm{AZT}+3 \mathrm{TC}+\mathrm{LPV} / \mathrm{r}$ in $3 \%(\mathrm{n}=3 / 100)$ of patients included.

Patients on a TDF-3TC-based regimen active against HIV and HBV represented $96 \%$ of the population. Those on a 3TC-only regimen accounted for $4 \%$.

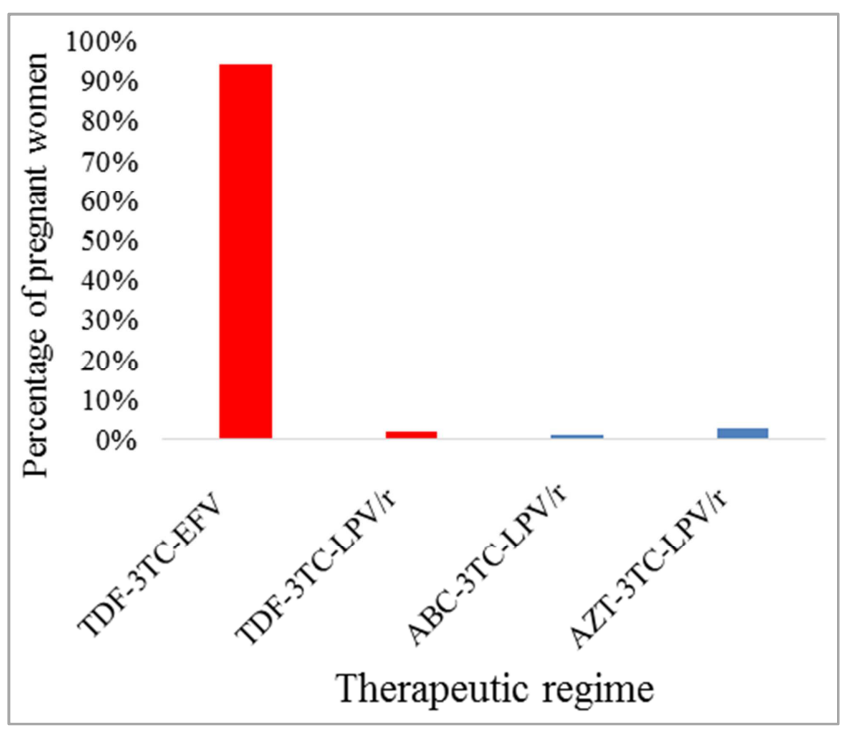

Figure 1. Treatment regimen for HIV-infected pregnant women.

Legend: TDF: Tenofovir; 3TC: Lamivudine; ABC: Abacavir; AZT: Zidovudine; LPV/r: Lopinavir boosted by ritonavir; EFV: Efavirenz.

In red: percentage of HIV-infected pregnant women with a therapeutic regimen based on two NRTIs (TDF+3TC) active against HBV and HIV.

Blue: percentage of HIV-infected pregnant women with a therapeutic regimen based on one NRTI (3TC) active against
HBV and HIV.

\subsection{HBV and HCV Serology Determination in Pregnant Women}

The figure shows the results of HBV and HCV serology in HIV-infected women obtained with the Elecsys HBsAg II and Elecsys Anti-HCV II tests respectively.

We observed that HBV serology was negative for $94 \%$ of the women included. However, $6 \%$ of the patients had positive HBV serology (Figure 2). Thus, the seroprevalence of HBVsAg in HIV-infected pregnant women was $6 \%$ in the present study.

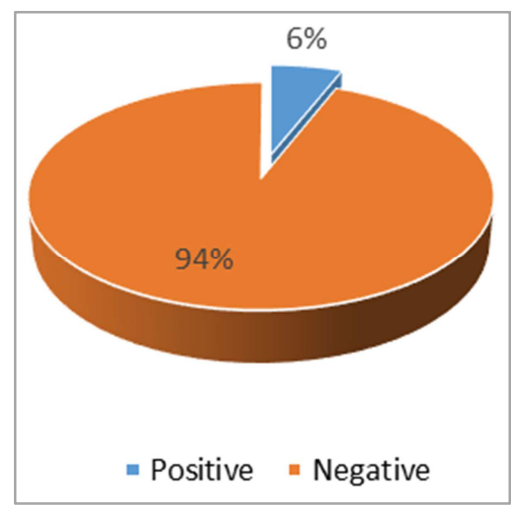

Figure 2. $H B V$ serological testing among $H I V$-infected pregnant women on $A R V$, between 2017 and 2018 at CIRBA, Abidjan.

The median age of included HBsAg-positive patients was 38 (32-44 years). The median HIV-1 RNA level was 20 copies/mL. Indeed, $100 \%$ of the women included had an HIV-1 RNA level below the threshold of detectability (HIV-1 RNA $<20$ copies $/ \mathrm{mL}$ ). The median ALAT level was $23 \mathrm{IU} / \mathrm{mL}$ (with a range of 8-38 IU/mL) Table 2 .

The table 2 shows that all HIV and HBV infected pregnant women in the study were on a treatment regimen of lamivudine (3TC) and tenofovir (TDF). And illustrate the $\mathrm{HCV}$ prevalence in this population. In this table, we observed that HCV serology was negative for $100 \%(n=100 / 100)$ of the included patients.

Table 2. Characteristics of pregnant women infected with HIV and HBV or HCV enrolled in the study.

\begin{tabular}{lll}
\hline Characteristics & Co-infected VHB-VIH & Co-infected VHC-VIH \\
\hline Numbers (n; Total) & $(6 ; 100)$ & $(0 ; 100)$ \\
Median age (year; range) & $38(32-44)$ & - \\
Median ALT (UI/mL) & $23(8-38)$ \\
Median HIV-1 RNA level (copies/mL) & 20 & - \\
Treatment regimens with NRTIs & \\
3TC $(\%)$, but no TDF & 0 \\
TDF +3 TC $(\%)$ & 6 \\
\hline
\end{tabular}

\subsection{Risk Factors for Transmission of Viral Hepatitis B or C}

The risk factors for $\mathrm{HBV}$ or $\mathrm{HCV}$ transmission like surgery were recorded in the patient's medical record during HIV management or collected during the enrollment. Of the 100 HIV-infected pregnant women included in this study, 23\% had undergone surgery. In this population, $\mathrm{HBs} A g$ was positive in $9 \%$ of patients and $\mathrm{HCV}$ antibodies were negative in all patients.

\section{Discussion}

In this study, we determined the seroprevalence of HBV or $\mathrm{HCV}$ infections in HIV-infected pregnant women on ARVs followed up or coming to CIRBA for routine examinations. 
The recommendations of the expert group on the medical management of people living with HIV and the National AIDS Control Program, advocate NRTI-based triple therapy (TDF+3TC) in case of HIV-HBV co-infection [5, 8]. In this study, $96 \%$ of HIV-infected pregnant women were on NRTIbased ARVs (TDF+3TC) and only $4 \%$ on 3TC active on HBV and HIV for at least one year. The result among HIV pregnant women on TDF+3TC in the present study is higher than that of Mpody and collaborators in the Hepatitis B infection in pregnant women living with HIV on ARVs study in Congo [9]. These authors had found that all HIV pregnant women were on NRTIs active against HIV and HBV, but $85 \%$ of included patients were on the TDF+3TC combination [9]. In contrast, patients on 3TC alone, estimated at $14 \%$ were higher than those on 3TC in this same study. The high percentage of HIV-infected pregnant women on TDF+3TCbased NRTIs could be explained by the fact that the risk of vertical transmission of HIV and HBV infections is high in low-income countries like Côte d'Ivoire. According to UNAIDS, to reduce the risk of vertical transmission, approximately $79 \%$ of pregnant women living with HIV worldwide are using antiretroviral therapy, primarily tenofovir and lamivudine-based combination antiretroviral therapy (ART) [10]. Indeed, the increased access to tenofovir for HIV treatment makes it a feasible option for prevention of mother-to-child transmission (PMTCT) of HBV according to Andersson and colleagues [6]. In the present study, 92\% of included patients had normal ALAT levels and 70\% had HIV-1 RNA levels below the threshold of detectability (HIV1 RNA $<20$ copies $/ \mathrm{mL}$ ). The percentage of HIV-infected pregnant women stable on ARVs was higher than that of Yotebieng and collaborators, who estimated an undetectable HIV-1 RNA level of $62 \%$ among HIV-1 infected pregnant women in Kinshasa [11]. However, this rate of pregnant women with undetectable viremia is lower than the goals set by WHO, which would be to achieve a sustainably suppressed viremia rate for $90 \%$ of PLHIV receiving antiretroviral treatment [12].

Table 3. HIV-infected patients who underwent surgery during HIV infection.

\begin{tabular}{ll}
\hline Characteristics & Values \\
\hline Patients with surgery (N) & 23 \\
Median age (year; range) & $35(27-44)$ \\
Surgical intervention (\%) & \\
Cesarean section & 65 \\
Ovarian cyst surgery & 4 \\
Lower limb surgery & 4 \\
Appendectomy & 23 \\
Mammary cystectomy & 4 \\
Umbilical hernia & 4 \\
Serology tests results (\%) & \\
HBsAg HBV & \\
Positive & 9 \\
Negative & 81 \\
Ac Anti-HCV & \\
Positive & 0 \\
Negative & 100 \\
\hline
\end{tabular}

Current World Health Organization (WHO) antiretroviral therapy (ART) guidelines define virologic failure as two consecutive viral load (VL) measurements $\geq 1,000$ copies $/ \mathrm{mL}$ [13]. In our study a significant number of these pregnant women had low viremia below the 1000 copies/mL WHO's threshold (27\%). Studies show that resistance associated mutations (RAMs) can be selected at lower replication rates. In a cohort in Lesotho, Brown et al found that $81 \%$ of individuals remaining on the same first-line regimen at low replication levels had high levels of resistance to at least two of their treatment molecules. These data support the lowering of the viral load threshold for treatment change and the case for wider access to this viral load testing for patient monitoring.

Thus, treatment adherence should be strengthened among pregnant women in Côte d'Ivoire. In order to significantly reduce, mother-to-child transmission of HIV and HIV resistance to ARV treatments which includes NRTIs also active on HBV in case of HIV-HBV coinfection.

To assess the seroprevalence of hepatitis $B$ and $C$ in pregnant women in the present study, HBV HBsAg and $\mathrm{HCV}$ antibody serological tests were performed.

The results of the HBsAg serology test revealed that $6 \%$ of HIV-infected pregnant women had positive HBV serology in our study. This seroprevalence is lower than that observed by Rouet and collaborators, who showed that HBV co-infection among HIV-infected pregnant women in Côte d'Ivoire was 9\% [14]. In contrast, other studies in African countries have shown lower seroprevalences than those obtained in this study: in Rwanda it was 4.1\% [15], 3.3\% in Congo [9], 3.1\% in South Africa [16]. Although HBV seroprevalence among pregnant women is decreasing in our study compared to Rouet and collaborators [14]. The risk of HBV infection among HIV-infected pregnant women still remains high because there is a great lack of knowledge of the modes of transmission and means of prevention to avoid viral hepatitis contamination in Côte d'Ivoire according to Enel and collaborators [17].

Regarding seroprevalence for HCV, $100 \%$ of HIV-infected pregnant women had negative serology. The absence of HIVHCV co-infections in our study would probably be due to the choice and size of the study population. This should not obscure the estimated HCV circulation of $4.3 \%$ in West Africa in mono-infected patients according to Ekouevi and collaborators [18] and $2.5 \%$ in Côte d'Ivoire [17]. Indeed, $\mathrm{N}$ 'din and collaborators confirmed the circulation of $\mathrm{HCV}$ strains of genotype 1, 2, 4 and 17 other subtypes in Côte d'Ivoire [19].

In addition, in this study $23 \%$ of the included patients had undergone surgery, which is a major risk factor for HBV or $\mathrm{HCV}$ transmission. Although, the introduction of systematic screening programs for blood products and improved sterilization procedures has greatly reduced the spread of viral hepatitis through these routes worldwide [20]. There are still risk factors for transmission of viral hepatitis B and C in medical practice. In the present study, $9 \%$ of the included patients who had undergone surgery during HIV management were HBsAg positive. This result is similar to one of the first studies conducted between 1984 and 1993 on risk factors for 
viral hepatitis transmission in the hospital setting. This study showed that 10 clusters associated with HBV-infected surgeons were documented in England with a rate of transmission to patients of $0.3-9 \%[21,22]$. In a recent study by Minuk and collaborators in 2020, glove failure, skin lesions, long duration of surgery and use of blood products were minor risk factors for transmission of viral hepatitis $\mathrm{B}$ or $\mathrm{C}$ during surgery [22].

According to these authors, in the majority of cases, there were no identifiable causes for the surgical outbreaks, the most likely explanations were related to needle sticks incurred during suturing and accidental cuts through gloves during knot tying. In our study, other risk factors such as intravenous drug use, history of tattooing, piercing, having a close relative with $\mathrm{HCV}$, use of recyclable medical equipment and certain traditional practices in Africa such as ethnic scarification and female circumcision have not been documented.

\section{Conclusion}

The seroprevalence of HBV infection was estimated to be $6 \%$ in the included patients. In contrast, no HIV-infected pregnant women had HIV-HCV co-infection in the present study. The data from this study support the implementation of large-scale sentinel surveillance in Cote d'Ivoire in order to refine data on the prevalence and circulation of viral hepatitis $\mathrm{B}$ and $\mathrm{C}$ in high-risk populations such as pregnant women. These data will allow the development of innovative strategies for the prevention and control of viral hepatitis in pregnant women in a context where nucleoside reverse transcriptase inhibitors (NRTIs) can be hepatotoxic and where direct-acting antivirals are not always available.

Studies reported that risk of end-stage liver disease (ESLD), cirrhosis and hepatocellular carcinoma (HCC), caused by HCV and HBV are increasing in HIV coinfected patients as their life expectancy is getting longer with successful highly active antiretroviral therapy (HAART) compared with those infected with HIV alone. Therefore, as with HIV testing, early detection of $\mathrm{HBV}$ and $\mathrm{HCV}$ are critical steps for optimal early therapeutic management. Screening and early diagnosis of chronic HBV and HCV infection allows individuals to obtain the care and treatment needed to prevent or delay the progression of liver disease [23]. Screening can also help reduce the spread of viral hepatitis through risk behavior counseling and interventions that provide hepatitis $\mathrm{B}$ prevention and vaccination products.

\section{Ethical Considerations}

The study was approved by the National Ethics Committee for Life Sciences and Health (CNESVS) (reference numbers: 027/MSHP/CNER-kp of 16 March 2017).

\section{Conflict of Interest}

The authors declare that they have no competing interests.

\section{Acknowledgements}

We thank the virology laboratory of the Abidjan Integrated Centre for Bioclinical Research (CIRBA) and the Pharmacodynamics-Biochemistry laboratory of the Biosciences UFR University Félix Houphouët-Boigny (UFHB) for carrying out this study.

We also thank the participants of this study.

\section{References}

[1] Silva, C. M., Peder, L. D., Guelere, A. M., Horvath, J. D., Silva, E. S., Teixeira, J. J., Bertolini, D. A. (2018). Seroprevalence of hepatitis B virus (HBV) and hepatitis C virus (HCV) in human immunodeficiency virus (HIV)infected patients in a HBV-endemic area in Brazil. PLOS ONE, 13 (9): e0203272.

[2] Muriuki, B. M., Gicheru, M. M., Wachira, D., Nyamache, A. K. \& Khamadi S. A. (2013). Prevalence of hepatitis B and $\mathrm{C}$ viral co-infections among HIV-1 infected individuals in Nairobi, Kenya. BMC Research Notes, 6: 363.

[3] World Health Organization (2017). World Hepatitis Report, 2017. 2017. http://www.who.int/hepatitis/publications/globalhepatitis report2017.

[4] Girard, P. M., Katlama, C. \& Pialoux, G. (2011). HIV. 2011th ed. France: Rueil-Malmaison, 839 p.

[5] National AIDS Control Program, (2015). 2015 uidelines for the care of people living with HIV in Côte d'Ivoire. 2015.

https://aidsfree.usaid.gov/sites/default/files/ci directives 2_2015_vih.pdf/ accessed on 05/19/2019.

[6] Andersson, M. I., Maponga, T. G., Ijaz, S., Theron, G., Preiser, W. \& Tedder, R. S. (2012). Elevated HBV viral loads in HIV-infected pregnant women in a tertiary hospital, South Africa. J Acquir Immune Defic Syndr. 60 (4): 2-111.

[7] Boa, A., Douba, A., N'Guessan, T. B., Menan, H., Attia, A., Ouassa, T., Bénié, J. B., Abokon, A., Dosso, M., Aholi, P., Timité-Konan, M., Abauleth, R. Y., Bissagnéné, E., Aka, J., Yavo, J. C., Sylvain, B. J., Ouattara, GS, Ekra, D. K, Sow, K., Kouassi, J. N., Ahoussou, E. M., Dally, R. K. (2017). [An advocacy for the introduction of hepatitis B vaccination at birth in Côte d'Ivoire]. Public Health, 29 (5): 751-760.

[8] Yeni P. (2018). Medical management of people living with HIV. Infections in adults: prophylaxis and curative treatments, www.corevih971.org/docrestreint.api/1789/.../pdf/expertsvih infections-3.pdf. Accessed on 05/19/2019.

[9] Mpody, C., Thompson, P., Tabala, M., Ravelomanana, N. L., Malongo, F., Kawende, B., Behets, F., Okitolonda, E., Yotebieng, M., (2019). CQI-PMTCT study team. Hepatitis B virus infection in pregnant and postpartum women living with HIV and on antiretroviral therapy in Kinshasa. antiretroviral therapy in Kinshasa, DR Congo: A cross-sectional study. PLoS One, 14 (5): e0216293.

[10] UNAIDS, 2017. HIV Fact Sheets. http://aidsinfo.unaids.org/ accessed on $05 / 19 / 2019$. 
[11] Yotebieng, M., Mpody, C., Ravelomanana, N. L., Tabala, M., Malongo, F., Kawende, B., Ntangu, P., Behets, F. \& Okitolonda, E. (2019). HIV viral suppression among pregnant and breastfeeding women in routine care in the Kinshasa province: a baseline evaluation of participants in CQI-PMTCT study. Journal of the International AIDS Society, 22: 2537625386.

[12] United Nations Organization on AIDS (UNAIDS), 2014. An ambitious treatment target to help end the AIDS epidemic Joint United Nations Programme on HIV/AIDS. 57 p.

[13] World Health Organization. Consolidated guidelines on the use of antiretroviral drugs for treating and preventing HIV Infection. Available at: www.who.int. 2016. Accessed on 07/14/2022.

[14] Rouet, F., Chaix, M. L., Inwoley, A., Msellati, P., Viho, I., Combe, P., Leroy, V., Dabis, F., Rouzioux, C. \& ANRS 1236 DITRAME-B \& C Study Group (2004). Prevalence and viremia of $\mathrm{HBV}$ and $\mathrm{HCV}$ in HIV-positive and HIV-negative pregnant women in Abidjan, Côte d'Ivoire: the ANRS 1236 study. J Med Virol, 74 (1): 34-40.

[15] Mutagoma, M., Balisanga, H., Malamba, S. S., Sebuhoro, D., Remera, E., Riedel, D. J., Kanters, S. \& Nsanzimana, S. (2017). Hepatitis B virus and HIV co-infection among pregnant women in Rwanda. BMC Infect Dis, 17 (1): 618.

[16] Thumbiran, N. V., Moodley, D., Parboosing, R. \& Moodley, P. (2014). Hepatitis B virus and HIV co-infection in pregnant women: indication for routine antenatal hepatitis B virus screening in a high HIV prevalence setting. $S$ Afr Med J, 104 (4): 9-307.

[17] Enel, C., Desgrées, du Lou A, N'Dri Y. T. \& Daniel L. (2015).
Viral hepatitis B and C in Côte d'Ivoire: the urgency of boosting control. African Journal of Hepato-Gastroenterology, 9 (3): 94-98.

[18] Ekouevi, D. K., Coffie, P. A., Tchounga, B. K., Poda, A., Jaquet, A., Dabis, F. \& Eholie, S. P. (2018). Prevalence of hepatitis C in HIV-1, HIV-2, and dual reactive patients: A multi-country cross-sectional survey in West Africa. J Public Health Afr, 9 (2): 871.

[19] N'din, J. L., Toni, T. D., Dechi, J. J. R., N'Guessan, J. F., Gogbe, L. O., Brou, E., A. A., Kouakou,. K., Chenal, H., Camara, C. M. (2018). Molecular characterization of hepatitis $\mathrm{C}$ virus strain circulated in chronically infected patients in Abidjan (Cote d'Ivoire). International Journal of Biochemistry, Bioinformatics and Biotechnology Studies, 3 (2): 20-28.

[20] Moufalilou, A. Aboudou, R. K. Bignon, R. G. Hermione Glago, Amel G. A. Zafy, H. M. \& Jean S. (2020). Prevalence and factors associated with $\mathrm{HCV}$ antibody carriage in pregnant women in Cotonou. Pan African Medical Journal. 36: 182 .

[21] Collins, M. \& Heptonstall, J. (1984). Occupational acquisition of acute hepatitis B infection by health care workers: England and Wales 1985-1993. Commun Dis Rep CDR Rev. 4: 153-5.

[22] Minuk, GY, Cohen, AJ, Assy, N., \& Moser, M. (2005). Viral hepatitis and the surgeon. HPB: the official journal of the International Hepato Pancreato Biliary Association, 7 (1), 5664.

[23] World Health Organization. GUIDELINES ON HEPATITIS B AND C TESTING FEBRUARY 2017. Available at: www.who.int. Accessed on 07/14/2022. 